\title{
Evidence for validity of ileal digestibility coefficients in monogastrics
}

\author{
Daniel Columbus and Cornelis F. M. de Lange* \\ Department of Animal and Poultry Science, University of Guelph, Ontario, Canada, N1G 2W1
}

(Submitted 20 August 2011 - Final revision received 23 November 2011 - Accepted 13 December 2011)

\begin{abstract}
Measures of amino acid (AA) digestibility are used widely to estimate bioavailability of AA in feed and food ingredients for monogastric animals. In principle, the digestibility assay is simpler than in vivo assessments of AA bioavailability and allows for simultaneous estimation of the bioavailability of all AA in an experimental diet. It is generally assumed that absorption of intact AA in the hindgut of monogastrics is minimal, even though colonocytes do contain AA transporters and have been shown to absorb AA. This assumption is supported by the observation that infusion of AA into the hindgut does not improve nitrogen balance in monogastrics. In addition, growth performance of monogastrics is more highly correlated with ileal than faecal AA digestibility. Therefore, ileal digestibility coefficients provide better estimates of AA bioavailability than faecal digestibility coefficients. Measures of apparent ileal digestibility (AID) of AA are confounded with endogenous gut AA losses (EAAL). The curvilinear increase in AID of AA with increasing dietary AA level has been attributed to the relatively large contribution of EAAL to total ileal AA flows at low dietary AA levels. Subtracting basal EAAL from total ileal AA flows yields standardized ileal digestibility (SID) coefficients that appear to be more additive than AID coefficients in mixtures of feed ingredients. An implicit assumption when using SID AA coefficients in diet formulation is that the post-absorptive utilization of AA is not influenced by the dietary protein source. This assumption appears inappropriate when using feed or food ingredients that have been over-heated, induce large amounts of EAAL, or contain substantial amounts of fermentable fibre. Improved understanding of processes that contribute to the discrepancy between bioavailability and ileal digestibility will allow a more effective use of AA digestibility coefficients in diet formulation.
\end{abstract}

Key words: amino acids: bioavailability: ileal digestibility: monogastrics

\section{Introduction}

Estimates of the bioavailability of amino acids (AA) in foods and feeds are required to properly meet dietary requirements for indispensible AA and nitrogen that are largely independent of dietary protein source and to assess the nutritional value of diverse dietary protein sources. Given the complexities associated with determining AA bioavailability, measures of digestibility are widely used in diet evaluation and formulation. However, the simplest measure of AA digestibility, apparent faecal digestibility, is confounded with enteric fermentation and endogenous gut protein losses from the host, which occur throughout the gastrointestinal tract. Both enteric fermentation and endogenous gut protein losses should be considered when extrapolating estimates of AA bioavailability from digestibility coefficients.

In this contribution, support is provided for the use of ileal digestibility coefficients for the routine assessment of bioavailability of AA in foods and feeds. In addition, the scientific basis is presented for using standardized ileal digestibility coefficients (i.e. apparent ileal digestibility coefficients that are corrected for basal endogenous gut AA losses) in the evaluation of diets for monogastrics. Finally, some of the limitations of using ileal digestibility coefficients in diet evaluation are discussed.

The experimental observations that are presented in this contribution are derived primarily from growing pigs. Pigs are a valuable research model for exploring concepts that are applicable to human nutrition, largely because of similarities in digestive physiology and our ability to apply a wide range of rather invasive surgical techniques to pigs ${ }^{(1)}$. The application of digestibility coefficients that have been obtained in pigs to human nutrition has been addressed elsewhere $^{(2,3)}$ and is addressed in other contributions to this special journal issue.

\section{Amino acid bioavailability and the digestibility assay}

As outlined by Fuller ${ }^{(4)}$, the bioavailability of a dietary AA can be defined as the proportion of the AA intake that is absorbed

Abbreviations: AA, amino acid; AID, apparent ileal digestibility; AFD, apparent faecal digestibility; EAAL, endogenous amino acid losses; SID, standardized ileal digestibility; TID, true ileal digestibility.

*Corresponding author: C. F. M. de Lange, fax +1-519-836-9873, email cdelange@uoguelph.ca 
in a chemical form that can be utilized for metabolic processes such as protein synthesis ${ }^{(5)}$. Accurate estimates of the bioavailable AA content of feeds and foods allow for greater precision when matching AA intake with AA requirements. However, currently no direct measures of bioavailability are available. Measures of AA digestibility are used widely to estimate AA bioavailability in feed and food ingredients for monogastrics, with the terms digestibility and bioavailability sometimes being used interchangeably and incorrectly. Slope-ratio assays are still considered the benchmark for determining (relative) bioavailability of AA in feeds and foods. This method involves supplying graded dietary levels of an individual AA from a particular protein source and measuring a response variable, such as whole body protein retention or AA oxidation ${ }^{(1,5)}$. Generally, the response to the test ingredient is compared with the response to a reference protein in which the AA bioavailability is known or is assumed to be $100 \%$, which yields relative estimates of bioavailability ${ }^{(5)}$. The slope-ratio assay is a time consuming, expensive, and laborious method that only provides a measure of bioavailability for one AA at a time. Moreover, estimates of bioavailability obtained with the slope-ratio assay may be confounded with endogenous AA losses, dietary nutrient imbalances, leading to incorrect estimates of bioavailability ${ }^{(6)}$ and may lack precision and/or repeatability ${ }^{(7)}$. It should be noted that when absorbed AA are all available for metabolism, bioavailability estimates obtained with this assay more closely represent apparent digestibility than true digestibility, as it reflects the net uptake of AA from the digestive tract. To evaluate bioavailability, as defined earlier, measures of true ileal digestibility combined with chemical availability are required. In principle, the digestibility assay is simpler than in vivo assessments of AA bioavailability and allows for simultaneous estimation of the bioavailability of all AA in an experimental diet or an individual diet ingredient. However, measures of digestibility are based on AA disappearance from the digestive tract and do not reflect the form in which AA and AA metabolites are absorbed ${ }^{(5)}$.

\section{Apparent faecal digestibility coefficients}

Apparent faecal, or total tract, digestibility (AFD) is the most basic in vivo method for estimating AA bioavailability and reflects disappearance of AA along the entire gastrointestinal tract. The faecal digestibility method has long been considered an inappropriate approach to determining AA bioavailability for monogastric animals, largely because of enteric fermentation in the hindgut ${ }^{(7)}$.

Undigested protein that enters the hindgut is susceptible to microbial degradation via deamination with carbon skeletons used as an energy source ${ }^{(8)}$. Studies have shown that protein, both of dietary and endogenous origin, is the major substrate for intestinal ammonia production ${ }^{(9-12)}$. Using an infusion of isotopic urea, it was determined that the contribution of urea hydrolysis to faecal ammonia in humans is less than $10 \%$ with the remainder derived from fermentation of undigested dietary and endogenous protein ${ }^{(9,10)}$. It has also been shown that an increase in protein flow into the hindgut results in an increase in digesta ammonia concentration ${ }^{(12)}$ providing further evidence that protein is the major substrate for gut ammonia production. Ammonia produced in the hindgut is readily absorbed by the animal, transported to the liver for ureagenesis, and excreted largely in urine. Therefore, the majority of nitrogen disappearance from the hindgut is likely due to fermentative losses and is of limited nutritional value to the animal.

Some studies, however, suggest the hindgut is not entirely incapable of AA absorption. Heine et al. ${ }^{(13)}$ demonstrated that when labelled yeast was infused into the colon of human infants, the majority of absorbed label (i.e. not excreted in faeces) was retained in body protein (i.e. not excreted in urine). The authors used these observations to conclude that the colon is capable of absorption of intact AA that can be utilized for metabolic processes. However, the ${ }^{15} \mathrm{~N}$-protein infused in this study may have been absorbed as non-protein nitrogen (i.e. ammonia) and utilized for endogenous production of dispensable AA or utilized in the upper gut for indispensable AA synthesis. The presence of AA transporters, such as the $\mathrm{ATBO}+$ and $\mathrm{B}^{\mathrm{O}+}$ transport systems, have been demonstrated in the colonic mucosa ${ }^{(14)}$ indicating the capacity for AA absorption. In addition, uptake of AA through the colonic mucosa has been demonstrated $^{(15,16)}$. However, it should be noted that measurement of AA uptake in these studies was done in isolated colonocytes grown in culture or on mounted sections of tissue and does not necessarily indicate what would occur in vivo. In addition, these studies were performed in newborn pigs in which it has been demonstrated that gut structure and function differs from older pigs. Indeed, it was shown that the ability of colonic tissue to transport AA was reduced in 4-day-old pigs and virtually eliminated in 10-day-old pigs ${ }^{(15)}$. This would suggest that the ability of the colon to absorb AA is lost quickly and would not be a significant factor in the growing pig and humans, except perhaps for young infants.

The inadequacy of using AFD coefficients to estimate AA bioavailability is further supported by a large number of studies in which protein or individual AA have been infused into the hindgut of pigs with little or no retention of the infused $\mathrm{AA}^{(17-22)}$. In several of these studies statistically insignificant improvements in whole body nitrogen retention were observed, suggesting that some of the experimental observations may not have been sufficiently sensitive to identify retention of AA that were infused into the hindgut ${ }^{(23)}$. However, in carefully controlled studies, and with AA that were limiting in the diet, infusion of AA into the hindgut of pigs did not improve whole body AA retention. For example, Darragh et al. ${ }^{(24)}$ infused lysine or methionine into the proximal colon of young pigs fed either lysine or methionine deficient diets with the assumption that nitrogen balance would be improved if the dietary indispensable AA were absorbed intact thus correcting the diet deficiency. However, no improvement in nitrogen balance was observed; in fact nitrogen balance was somewhat reduced when compared to pigs receiving additional lysine or methionine orally. Wünsche et al. $^{(22)}$ performed a similar study examining lysine and isoleucine infusion into the colon of animals receiving lysine or 
isoleucine deficient diets. Again it was found that while faecal digestibility was not affected by the infusion, nitrogen balance was decreased and urinary ammonia increased in these animals ${ }^{(22)}$. In another study, nitrogen digestibility and retention was compared in pigs in which a casein supplement was given orally or infused into the terminal ileum. Total tract nitrogen digestibility from the hindgut was decreased only slightly when casein was administered ileally, suggesting that nitrogen was being absorbed from the hindgut, but there was a significant reduction in nitrogen retention in these pigs [Zebrowska et al. (1978) as referenced in Buraczewski $\left.{ }^{(25)}\right]$, which indicates that nitrogen absorption from the hindgut was of no nutritional significance to the animal. In a review of studies in which casein was infused into the caecum of pigs, Fuller \& Reeds ${ }^{(26)}$ found that even though faecal digestibility was not different with casein infusion, indicating that nitrogen was being absorbed from the hindgut, there was little or no improvement in whole body nitrogen balance. This is consistent with the observation that nitrogen that is absorbed from the hindgut contributes primarily to urinary nitrogen excretion. Indeed, while it was shown that approximately $18 \%$ of total nitrogen absorption occurred in the colon of pigs ${ }^{(27,28)}$, the absorption of labelled nitrogen from the colon was entirely accounted for by label excretion in urine ${ }^{(28)}$.

The AA profile of faecal protein, and therefore AA digestibility, is extensively modified by enteric microbes, which can be attributed to both fermentative $\mathrm{AA}$ catabolism and de novo synthesis of microbial protein. As a result the AA profile of faecal protein bears little resemblance to the dietary AA profile and even to the AA present in ileal digesta. When comparing ileal and faecal digestibility values for lysine in different feed ingredients, Rademacher et al. ${ }^{(29)}$ demonstrated that there can be significant differences between the two measures and that faecal digestibility is not always the greater value. This demonstrates the combined effects of protein fermentation and microbial synthesis of AA in the hindgut of pigs and their effects on estimates of AA digestibility. The faecal digestibility method is therefore considered inappropriate with respect to determining AA bioavailability.

Only in two scenarios can ammonia absorbed from the hindgut provide a benefit in supplying nitrogen to the host $^{(30,31)}$. Firstly, when the amount of absorbed AA is insufficient to satisfy the host's demand for dispensable AA, ammonia may be used in transamination reactions yielding dispensible $\mathrm{AA}^{(30)}$. Secondly, urea that is generated from absorbed ammonia may be secreted, or recycled, into the gut and be used by microbes in the upper gut for the microbial production of indispensable and dispensable AA. Like dietary AA, microbially produced AA may be absorbed from the upper gut and can contribute to the supply of AA to the host. The latter has been shown to occur in pigs $^{(32-34)}$, humans ${ }^{(35-38)}$, and rats ${ }^{(39)}$. It has been estimated that about $30 \%$ of non-protein nitrogen that is generated in the pig's body is recycled into the gut and, therefore that only $70 \%$ of the whole body non-protein nitrogen flux is excreted in urine ${ }^{(26)}$. It can thus be speculated that recycling of non-protein nitrogen is an important contributor to nitrogen economy and impacts the host's utilization of indispensable AA and total nitrogen. It follows then that nitrogen disappearance from the hindgut due to protein fermentation, and thus AFD, may in some scenarios be important for meeting the total nitrogen needs of the animal. However, for both of these scenarios the efficiency of capturing ammonia that is generated in the hindgut, and therefore the net contribution of protein fermentation in the hindgut to the host's supply of dispensable and indispensable AA, remains to be quantified $^{(26)}$.

\section{Apparent ileal digestibility coefficients}

Amino acid disappearance from the gut proximal to the terminal ileum, reflected in apparent ileal digestibility (AID), is considered a better estimate of AA bioavailability than $\mathrm{AFD}^{(7,23)}$. The AID of AA largely represents enzymatic protein digestion and absorption of intact AA with some influence from microbial fermentation in the upper gut ${ }^{(40)}$. In order to determine AID coefficients digesta samples must be obtained from the distal ileum. The latter requires rather invasive sampling methods, involving the use of surgically modified subjects and digestibility markers. Practical aspects of sampling ileal digesta from animals and humans are addressed by Fuller ${ }^{(4)}$. Caution must be used when using protein or nitrogen digestibility as an indicator of AA digestibility since there can be considerable differences between the digestibility values for individual $\mathrm{AA}^{(41,42)}$.

In pigs several studies have shown that AID values provide more accurate estimates of AA bioavailability than $\operatorname{AFD}^{(29,41,43-45)}$ and that AID is a more sensitive assay than AFD for identifying differences in nutritional value among protein sources $^{(46-48)}$. For example, Low et al. ${ }^{(44)}$ and Just et $a{ }^{(45)}$ showed that growth performance and body protein gain of pigs is more highly correlated with ileal rather than faecal protein digestibility. Just et al. ${ }^{(45)}$ determined AID and AFD of AA and protein in 24 diets and found that nitrogen retention was slightly more correlated with ileal rather than faecal digestible daily crude protein intake (0.81 vs. 0.75$)$. However, AID and AFD intake of AA and nitrogen are highly confounded across diets in this study and the dietary AA balances vary among the diets and, therefore, these findings should be interpreted with caution. In contrast, Dierick et al. ${ }^{(49)}$ compared feed efficiency in 8 diets formulated to contain similar levels of faecal digestible protein, total dietary lysine, and ratios among key indispensable AA but to differ in ileal digestible nitrogen content. It was determined that there was a higher correlation between feed efficiency ( 0.87 vs. 0.65$)$ or growth rate $(0.76$ vs. 0.34$)$ and ileal nitrogen digestibility vs. faecal nitrogen digestibility. Moreover, it was shown that pig performance suffered as ileal digestibility of protein decreased ${ }^{(49)}$. Moughan \& Smith ${ }^{(41)}$ and Rademacher et $a l .{ }^{(29)}$ showed that AID values accurately predicted AA bioavailability. Rademacher et $a l^{(29)}$ formulated diets with decreasing amounts of AID lysine by replacing soyabean meal with canola meal, meat meal, alfalfa meal, beet pulp, and wheat bran in which the AID of lysine was previously determined. It was shown that as the amount of AID lysine 
was decreased in the diets the growth performance of the pigs decreased confirming the validity of using AID values for estimating lysine bioavailability ${ }^{(29)}$. Likewise, Moughan \& Smith $^{(41)}$ determined the AID of lysine in barley, meat and bone meal, fish meal, and pea meal and then compared the growth performance and carcass measures in pigs fed a diet based on all the protein sources to a casein based diet formulated to have the same level of AID lysine as the barley diet. Mough \& Smith ${ }^{(41)}$ found no difference between any of the measured responses between the two diets and concluded that the AID lysine in each feedstuff could be used to accurately formulate and predict the AID lysine content of a complete diet.

The benefit of using AID coefficients is also demonstrated when comparing the differences in protein quality among and within foods, feeds, and dietary protein sources. For example, Sauer et al. ${ }^{(47)}$ showed that unlike AFD, AID coefficients differed among four sources of barley. In a study by Holmes et $a l{ }^{(50)}$ comparing AID and AFD of nitrogen and AA between soyabean meal and rapeseed meal in pigs, it was found that while AID values for soyabean meal correlated well with AFD values, this was not the case for rapeseed meal. Moreover, the difference between nitrogen digestibilities at the faecal level for these two protein sources was much less than observed at the ileal level. On average, Austic ${ }^{(51)}$ reported that AFD is 6.5 percentage units higher than AID and that this discrepancy becomes greater (ileal digestibility lower and/or faecal digestibility higher) for low digestibility protein sources. This is likely a combination of decreased digestibility and increased excretion of microbial protein when high-fibre feedstuffs are included in diets. Sauer et al. ${ }^{(47)}$ showed that measures of ileal digestibility are more sensitive than faecal digestibility and can be used to identify the impact of diet processing on the nutritional value of protein sources.

It should be noted that in some instances AID coefficients overestimate AA bioavailability, especially for lysine in heatprocessed protein sources, for threonine in diets containing large amounts of fermentable fibre, and when large endogenous gut protein losses are incurred. This will be addressed in further detail in a subsequent section of this review.

A critical issue with AID coefficients is the curvilinear increase in AID of AA with increasing dietary AA content, which occurs even when the dietary AA content is altered by varying the inclusion level of a particular protein source in the diet (Fig. 1) ${ }^{(52)}$. This variability in AID coefficients for individual protein sources raises concerns about the impact of protein levels used in experimental diets to establish AID coefficients and about the lack of additivity of AID coefficients among food or feed ingredients. By considering the impact of endogenous gut protein losses on AID coefficients these concerns can largely be overcome.

\section{Endogenous gut amino acid losses and ileal digestibility coefficients}

Measures of AID of AA are confounded with endogenous gut AA losses (EAAL). The EAAL represent AA and synthesized proteins that are secreted into the intestine and are not reabsorbed prior to the terminal ileum, and originate from saliva, gastric secretions, bile, pancreatic juice, digestive enzymes, sloughed epithelial cells, and mucins ${ }^{(53-55)}$. The amount of protein from endogenous origin may exceed the amount of ingested dietary protein and is, just like dietary protein, partly digested and absorbed. Since endogenous secretions cannot be distinguished from dietary proteins in conventional digestibility studies, ileal digestibility coefficients that are not corrected for EAAL should be referred to as AID coefficients ${ }^{(5)}$.

The curvilinear increase in AID of AA when increasing the dietary AA content (Fig. 1) can largely be attributed to the relatively large contribution of EAAL to total ileal AA flows at low dietary AA levels ${ }^{(52)}$. This is further illustrated in Fig. 2, in which the AID coefficients for methionine that are provided in Fig. 1 are used to calculate total ileal methionine flow per unit of feed DM intake. Figure 2 shows a highly linear relationship between total ileal methionine flow and the dietary methionine level. Similar highly linear relationships between ileal AA flow and dietary AA level have been shown for other indispensable AA and in studies in which five or more dietary protein levels have been evaluated ${ }^{(52,56)}$ The impact of dietary AA level on AID of AA (Fig. 1) can thus be attributed fully to the intercept of the relationship between total ileal AA flow and dietary AA level (Fig. 2). Furthermore, the slope of the linear relationship between total ileal AA flow and dietary AA level represents an important measure of digestibility. Historically, it was assumed that the increase in total ileal AA flow with increasing dietary AA level could be attributed entirely to an increased flow of undigested dietary AA. Hence this slope was used to derive estimates of 'true' ileal AA digestibility. However, by using more advanced techniques, which allow for separate identification of endogenous and dietary AA in ileal digesta, it has been shown that increases in total ileal AA flows can generally be attributed to increase in flow of both EAAL and dietary AA ${ }^{(54)}$. Therefore, at least two components of EAAL can be identified: (1) the basal EAAL, represented by the intercept in Fig. 2, and

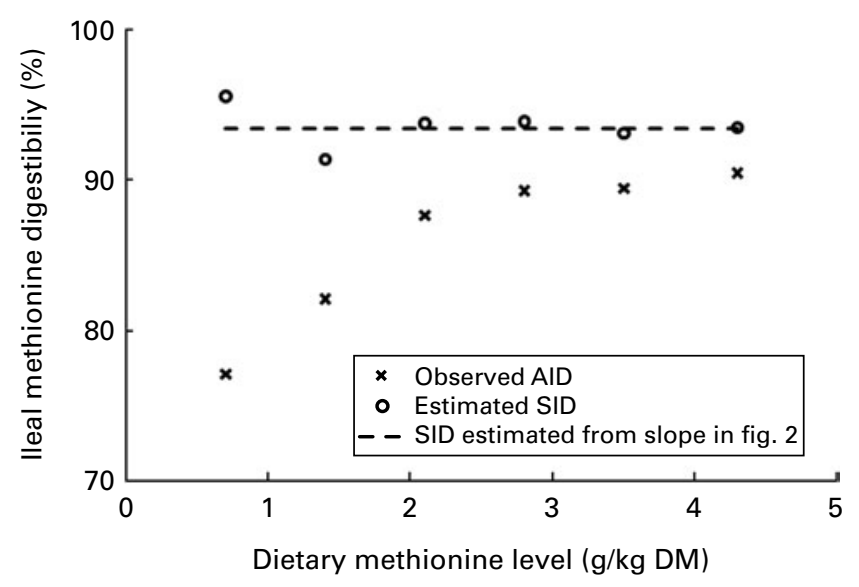

Fig. 1. Impact of dietary methionine level on observed apparent ileal digestibility (AID) and estimated standardized ileal digestibility (SID) of methionine in growing pigs [adjusted from Fan et al. ${ }^{(52)}$; variable dietary methionine levels are the result of varying the level of soyabean meal across diets; SID coefficients were established by subtracting basal endogenous ileal methionine loss from total ileal methionine flows for each measurement of AID of methionine (Fig. 2)]. 


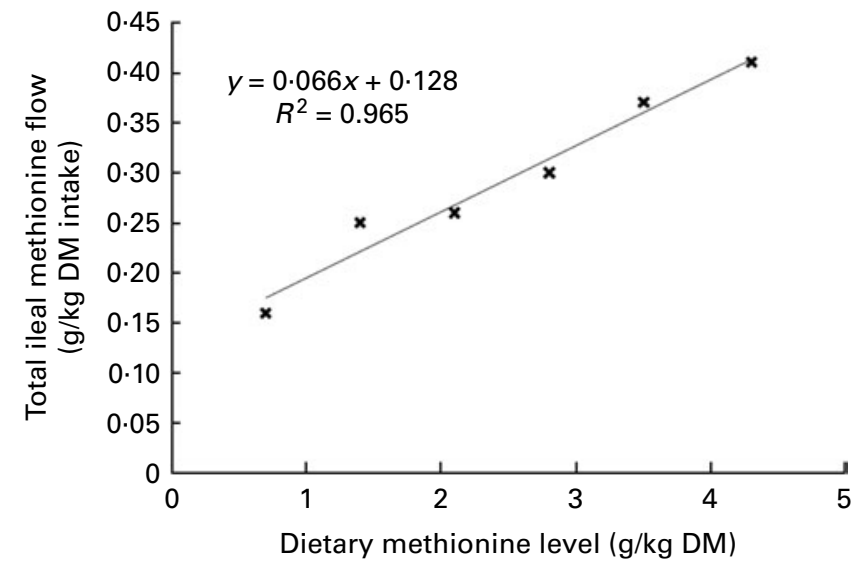

Fig. 2. Impact of dietary methionine level on total ileal flow of methionine in growing pigs [adjusted from Fan et al. ${ }^{(52)}$; variable dietary methionine levels are the result of varying the level of soyabean meal across diets; the basal endogenous ileal methionine loss $(0.1289 \mathrm{~g} / \mathrm{kg}$ DM intake) was estimated based on linear regression analyses and extrapolation to feeding a methioninefree diet; the slope of the line of best fit (0.066) yields an estimate of SID of methionine, which is equivalent to the horizontal line representing estimated SID of methionine in Fig. 1: SID $=100 \times(1-$ slope $)$.

(2) ingredient specific EAAL. Basal EAAL may be related to DM intake, which is the approach that has been adopted widely in animal nutrition ${ }^{(57)}$, or to the host's metabolic state (e.g. some measure of metabolic body weight), including the host's (gut) health status. The latter may be more appropriate for mature individuals or when levels of food intake are low. This is the case in humans where food intake can be considered low relative to the levels of feed intake observed in highly productive farm animals. The specific EAAL are induced when increasing amounts of different protein sources, fibre, or other EAAL inducing compounds (e.g. anti-nutritional factors such as tannins, lectins, trypsin inhibitors) are included in the diet ${ }^{(54,58)}$.

To differentiate between ileal digestibility coefficients that are corrected for total EAAL (true ileal digestibility; TID; sometimes also referred to as real ileal AA digestibility) and ileal digestibility coefficients that are corrected for basal EAAL only, a new term was introduced: standardized ileal AA digestibility (SID $)^{(5,54)}$. The concept of SID coefficients has been adopted around the world for the formulation of pig diets and extensive databases summarizing SID coefficients for AA in a wide range of feed ingredients have been published ${ }^{(59-61)}$. The main advantages of using SID coefficients in feed formulation is that they are independent of dietary AA level, reduce variability in measures of ileal digestibility within food and feed ingredients, are more additive than AID coefficients in mixtures of feed or food ingredients, and can be derived experimentally without too much difficulty by correcting AID for basal EAAL ${ }^{(5,54,62)}$. Many studies have been conducted to quantify basal EAAL in pigs. In a review of the literature, Jansman et al. ${ }^{(57)}$, suggested that the mean estimate of basal endogenous ileal lysine losses observed in studies where pigs were fed protein-free diets $(0.36 \mathrm{~g}$ per $\mathrm{kg}$ DM intake; SD $0 \cdot 10 ; 16$ studies) was similar to estimates obtained based on regression analyses, as outlined in Fig. 2 (0.38; SD 0.09; 3 studies) and only slightly lower than estimates obtained from pigs fed purified proteins with an assumed TID of $100 \%(0 \cdot 44 ;$ SD $0 \cdot 17 ; 11$ studies). Relative differences were similar for other indispensable AA. It should be noted that estimates of basal EAAL vary between laboratories, even when using identical methodology, and that it is appropriate to obtain local estimates of EAAL when determining AID coefficients for calculating TID coefficients for $\mathrm{AA}^{(5,63)}$. Until a methodology is in place to routinely measure total EAAL, both basal and diet specific, and these losses have been quantified for a wide range of feed ingredients, SID coefficients will provide the basis for estimated bioavailability of AA in feeds and foods.

When advanced methods have been used to estimate total EAAL, and thus specific EAAL, it has been shown that the specific EAAL varies among protein sources and feed ingredients. For example, when de Lange et al. ${ }^{(64)}$ used an ${ }^{15} \mathrm{~N}$ isotope dilution technique, they estimated total ileal endogenous lysine losses to be $1 \cdot 02,1 \cdot 22,1 \cdot 10$ and $1 \cdot 11 \mathrm{~g}$ per $\mathrm{kg}$ feed DM intake (SE 0 10) in growing pigs fed diets that contained soyabean meal, canola meal, wheat, or barley as the only protein source, respectively. These values were all higher than values obtained in pigs that were managed under similar conditions and that were fed either a protein-free diet (0.63) or protein-free diets with a simultaneous intravenous infusion of a mixture of indispensable and dispensable AA $(0.56 \mathrm{~g}$ per kg DM intake; SE 0.07) ${ }^{(65)}$. These observations also illustrate that endogenous gut AA are a major contributor to dietary $\mathrm{AA}$ requirements and that care should be taken in how EAAL are considered when estimating AA requirements. When diets are formulated based on SID coefficients, the specific EAAL are already accounted for in the nutritional value of the diet and only the basal EAAL, not the specific EAAL, should be considered explicitly when characterizing host or animal factors that contribute to AA requirements. When foods or feeds are evaluated based on TID coefficients, it is critical that both the basal and specific EAAL are considered as part of the animal or host factors contributing to AA requirements.

\section{Refinements to ileal digestibility coefficients for estimating amino acid bioavailability}

As mentioned above, in some instances SID, or AID, coefficients do not yield proper estimates of AA bioavailability and the confounding of EAAL and true digestible AA intake should be considered carefully when interpreting estimates of AA bioavailability, especially when these are obtained with the slope-ratio assay. As we move towards a better understanding of the discrepancy between ileal digestibility and bioavailability, refinements may be made to SID coefficients to routinely estimate AA bioavailability in feeds and foods and to better predict the host's response to varying AA intake form different protein sources. Here three specific examples of such refinements are provided.

\section{Lysine bioavailability in heat treated foods and feeds}

In a comparison of diets formulated to have the same level of AID lysine from expeller-extracted oil seed meal from either 
cottonseed or soyabeans, Prawirodigdo et al. ${ }^{(66)}$ found that nitrogen retention in grower pigs was lower with the cottonseed meal-based diet $(17 \cdot 3$ vs. $23 \cdot 3 \mathrm{~g} / \mathrm{d})$. In another study and when field peas were fed raw or heated to varying temperatures between 110 an $165^{\circ} \mathrm{C}$ it was demonstrated that heating had little impact on AID of lysine (e.g. $92 \%$ for raw peas vs. $84 \%$ for peas heated to $165^{\circ}$ ), while relative lysine bioavailability as determined in a slope-ratio assay was gradually reduced from $96 \%$ in raw peas to $18 \%$ for peas heated to $165^{\circ} \mathrm{C}^{(67)}$. In general, with heat-processed protein sources, the AID coefficients may overestimate lysine bioavailability ${ }^{(68)}$. However by integrating the chemical form of lysine in feed ingredients, based on the reactive lysine or equivalent assays, with AID or SID coefficients the impact of heat-processing on lysine bioavailability can be accommodated $^{(69,70)}$. This concept may also apply to other AA and is addressed in more detail by Rutherfurd ${ }^{(71)}$.

\section{Impact of soluble fibre intake on threonine utilization and enteric fermentation}

The inclusion of fibre in the diet can result in decreases in both apparent ileal and apparent faecal AA digestibility ${ }^{(72,73)}$. It is thought that this reduction in digestibility is due to a number of factors including increased $\mathrm{EAAL}^{(74)}$, impairment of nutrient absorption ${ }^{(72)}$, and an increase in nitrogen incorporation into microbial protein and thus increased microbial protein flow at the distal ileum or in faeces ${ }^{(75)}$. In addition, fibre can impact aspects of AA utilization that are not reflected in measures of digestibility. Libao-Mercado et al. ${ }^{(76)}$ found that the efficiency of utilization of SID threonine intake for whole body protein deposition was reduced when pigs were fed diets in which casein had been replaced by wheat shorts, a co-product from the wheat starch industry and with properties that are similar to those of wheat bran. It was suggested that this was due to the high fibre content of wheat shorts. This was confirmed in a follow-up study in which graded levels of pectin, a highly soluble and fermentable source of fibre, were fed to pigs. In this study it was shown that there was an increase in the fermentative loss of threonine in pigs fed increasing dietary pectin levels, reflected in an increase in urinary excretion of nitrogen ${ }^{(77)}$. In that study there was also an increase in faecal excretion of total nitrogen and microbial protein, which was associated with an increase in mucin and colonic mucosal protein synthesis ${ }^{(78)}$ and, by extrapolation, increased endogenous gut protein losses. The latter is supported by Hedemann et al. ${ }^{(79)}$ who found that the intestinal mucous layer was thicker in the colon of rats fed high-fibre diets. The high threonine content of mucins combined with the susceptibility of mucins to microbial degradation ${ }^{(80)}$ would explain the increase in threonine catabolism and the decrease in utilization efficiency of threonine.

A decrease in threonine utilization efficiency was not observed when purified cellulose, an insoluble and poorly fermentable source of fibre, was included in threonine limiting $\operatorname{diets}^{(77)}$, highlighting that the impact of dietary fibre on AA utilization is mediated primarily by its impact on enteric fermentation, likely in both the small intestine and hindgut.
A meaningful impact of additional pectin intake on utilization of other amino acids (lysine, methionine, tryptophan) for body protein deposition could not be detected ${ }^{(77,81,82)}$, which is consistent with the large contribution of threonine to EAAL, the use of endogenous gut protein as the substrate for enteric fermentation, and the stimulating effect of some fibre sources on enteric fermentation. Energy availability, and not nitrogen, from fermentable substrates has been shown to be a limiting factor for microbial protein production $^{(83)}$ and therefore the increase in available energy from fibre may result in an increase in microbial population and activity ${ }^{(84)}$.

These observations also highlight the potential impact of enteric fermentation in the upper gut of monogastrics on AA utilization. As described by Fuller ${ }^{(4)}$, enteric fermentation occurs in the upper gut of monogastrics and contributes to de novo microbial AA synthesis ${ }^{(32,33)}$ as well as (fermentative) catabolism of $\mathrm{AA}^{(11)}$. Libao-Mercado et al. ${ }^{(11)}$ determined that greater than $70 \%$ of ammonia production at the terminal ileum was due to fermentation of dietary and endogenous protein and not due to urea hydrolysis. Based on measured ammonia flow at the ileum it was estimated that $2 \cdot 1 \mathrm{~g}$ of protein per $\mathrm{kg}$ DM intake is catabolized by gut microbes ${ }^{(85)}$. Libao-Mercado ${ }^{(85)}$ stated that this was likely an underestimation of ammonia generation due to the absorption and utilization of ammonia prior to the ileum. In his review, $\mathrm{Wu}^{(86)}$ suggested that the reported $30 \%$ catabolism of the AA histidine, lysine, methionine, phenylalanine, threonine, and tryptophan by enterocytes in vivo and the lack of in vitro catabolism and activity of AA degrading enzymes for these AA in enterocytes suggests that the catabolism of AA is due to fermentation by intestinal microbes. The extent of fermentation will also depend on the individual AA, with lysine and arginine being rapidly fermented and methionine, cysteine, and branched-chain AA, being slowly or incompletely fermented ${ }^{(87)}$ resulting in overestimates for bioavailability of some AA and not others. Clearly, AA losses in the upper gut due to microbial fermentation may be extensive. Further investigation is required to quantify the impact of enteric fermentation in the upper gut on AID and SID of AA and on the net supply of AA to the host.

\section{Metabolic inefficiencies associated with endogenous gut protein losses}

As mentioned earlier, EAAL contribute to dietary AA requirements and care should be taken in how to account for basal and specific EAAL when evaluating the bioavailable AA content of foods and feeds. In additional to EAAL themselves, the metabolic costs associated with EAAL should be considered, simply because there is a metabolic inefficiency associated with synthesis and recycling (i.e. secretion and re-absorption) of endogenous gut proteins. The latter becomes even more relevant when one realizes that EAAL represent roughly only $25 \%$ of endogenous protein that is secreted into the gut and that the remainder is recycled ${ }^{(54)}$. The metabolic inefficiency can be attributed largely to AA catabolising enzymes that are present primarily in the liver and some of the other digestive organs ${ }^{(86)}$, to which AA are 
exposed during absorption and passage through the liver. Fermentative AA catabolism by enteric microbes can contribute to this metabolic inefficiency as well.

Until recently, very few well controlled studies have been conducted to quantify this metabolic inefficiency ${ }^{(88)}$. Lahaye et $a l{ }^{(89)}$ fed diets that induced varying endogenous ileal nitrogen losses to growing pigs, caused by differential processing, and established a relationship between total endogenous ileal nitrogen losses, measured based on isotope dilution, and whole body nitrogen retention. These researchers concluded that the metabolic costs associated with an increase in endogenous ileal nitrogen losses were in fact larger than the actual increase in endogenous ileal nitrogen losses themselves. Even when corrections were made for treatment effects on SID nitrogen intake, reductions in whole body nitrogen retention (12.6\%) appeared larger than increases in endogenous gut nitrogen losses (4.0\%). These observations suggest that metabolic costs associated with EAAL can be substantial and provide an important incentive to accurately quantify EAAL and its associated metabolic costs.

\section{Conclusions and implications}

There is a large body of evidence to suggest that in many instances measures of ileal amino acid (AA) digestibility yield reasonable estimates of bioavailability of AA in feeds and foods. A key limitation of using apparent ileal digestibility (AID) coefficients for diet evaluation and estimating AA requirements is that they are confounded with dietary AA levels. The latter can be attributed to the varying contribution of endogenous gut AA losses (EAAL) to total ileal AA flows. The EAAL can be separated into two main components, basal and ingredient specific EAAL. When correcting AID coefficients for basal EAAL only, standardized ileal digestibility (SID) coefficients are derived that are independent of diet AA level, less variable for a particular dietary ingredient, and more additive in mixtures in feed or food ingredients. The concept of SID is used extensively when formulating diets for monogastric farm animals. When using SID coefficients in diet evaluation, only the basal EAAL should be considered part of the animal or host effects on AA requirements. In some instances SID (as well as AID and TID) coefficients will provide inaccurate estimates of AA bioavailability, in particular bioavailability of lysine in heat treated ingredients, bioavailability of threonine in diets that contain large amounts of fermentable fibre, and that of $\mathrm{AA}$ in diets that induce large amounts of specific EAAL. The concept of SID coefficients may be refined for specific feeds and foods to account for instances where SID coefficients do not yield proper estimates of AA bioavailability.

\section{Acknowledgements}

D. Columbus and C.F.M. de Lange contributed equally to the preparation of this review. The authors state that there is no conflict of interest. This research received no specific grant from any funding agency in the public, commercial or not-for-profit sectors.

\section{References}

1. Fuller MF \& Tome D (2005) In vivo determination of amino acid Bioavailability in humans and model animals. $J A O A C$ Int 88, 923-934.

2. Rowan AM, Moughan PJ, Wilson MN, et al. (1994) Comparison of the ileal and faecal digestibility of dietary amino acids in adult humans and evaluation of the pig as a model animal for digestion studies in man. Br J Nutr 71, 29-42.

3. Deglaire A, Bos C, Tome D, et al. (2009) Ileal digestibility of dietary protein in the growing pig and adult human. BrJ Nutr 102, 1752-1759.

4. Fuller M (2012) Determination of protein and amino acid digestibility in foods including implications of gut microbial amino acid synthesis. Br J Nutr 108, S238-S246.

5. Stein HH, Seve B, Fuller MF, et al. (2007) Invited review: Amino acid bioavailability and digestibility in pig feed ingredients: Terminology and application. J Anim Sci $\mathbf{8 5}$, 172-180.

6. Langer S \& Fuller MF (2000) Interactions among the branched-chain amino acids and their effects on methionine utilization in growing pigs: effects on nitrogen retention and amino acid utilization. Br J Nutr 83, 43-48.

7. Sauer WC \& Ozimek L (1986) Digestibility of amino acids in swine: results and their practice applications. A review. Livest Prod Sci 15, 367-388.

8. Vince A, Dawson AM, Park N, et al. (1973) Ammonia production by intestinal bacteria. Gut 14, 171-177.

9. Wrong OM, Vince AJ \& Waterlow JC (1985) The contribution of endogenous urea to fecal ammonia in man, determined by N-15 labeling of plasma urea. Clin Sci 68, 193-199.

10. Wrong OM \& Vince A (1984) Urea and ammonia metabolism in the human large-intestine. Proc Nutr Soc 43, 77-86.

11. Libao-Mercado AJO, Zhu CL, Cant JP, et al. (2009) Dietary and endogenous amino acids are the main contributors to microbial protein in the upper gut of normally nourished pigs. J Nutr 139, 1088-1094.

12. Mouille B, Robert V \& Blachier F (2004) Adaptive increase of ornithine production and decrease of ammonia metabolism in rat colonocytes after hyperproteic diet ingestion. $\mathrm{Am}$ J Physiol Gastr L 287, G344-G351.

13. Heine W, Wutzke KD, Richter I, et al. (1987) Evidence for colonic absorption of protein nitrogen in infants. Acta Paediatr Scand 76, 741-744.

14. Blachier F, Mariotti F, Huneau JF, et al. (2007) Effects of amino acid-derived luminal metabolites on the colonic epithelium and physiopathological consequences. Amino Acids 33, 547-562.

15. James PS \& Smith MW (1976) Methionine transport by pig colonic mucosa measured during early post-natal development. J Physiol 262, 151-168.

16. Smith MW \& James PS (1976) Amino acid transport by the helicoidal colon of the new-born pig. Biochim Biophys Acta 419, 391-394.

17. Zebrowska T (1973) Digestion and absorption of nitrogenous compounds in the large intestine of pigs. Rocz Nauk Rol 95, 85-89.

18. Sauer WC (1976) Factors Influencing Amino Acid Availability for Cereal Grains and their Components for Growing Monogastric Animals, PhD ed. Winnipeg, Canada: University of Manitoba.

19. Hodgdon ES, Horney FD \& Bayley HS (1977) Nitrogen metabolism in pigs receiving soybean and rapeseed meal. Can J Anim Sci 57, 832. 
20. Gargallo J \& Zimmerman D (1981) Effect of casein and starch infusion in the large intestine on nitrogen metabolism of growing swine. J Nutr 111, 1390-1396.

21. Just A, Jorgensen H \& Fernandez JA (1981) The digestive capacity of the caecum-colon and the value of nitrogen absorbed from the hindgut for protein synthesis in pigs. Br J Nutr 46, 209-219.

22. Wunsche J, Hennig U, Meinl M, et al. (1982) Investigations of the absorption and utilization of amino-acids infused into the cecum of growing-pigs 1 . N-balance measuring with regard to the utilization of lysine and isoleucine and the isoleucine requirement of growing-pigs. Arch Tierernabr 32, 337-348.

23. Moughan PJ (2003) Amino acid availability: aspects of chemical analysis and bioassay methodology. Nutr Res Rev 16, 127-141.

24. Darragh AJ, Cranwell PD \& Moughan PJ (1994) Absorption of lysine and methionine from the proximal colon of the piglet. Br J Nutr 71, 739-752.

25. Buraczewski S (1980) Digestion of proteins and absorption of amino acids in the digestive tract of pigs. Arch Tierernabr 30, 29-40.

26. Fuller MF \& Reeds PJ (1998) Nitrogen cycling in the gut. Annu Rev Nutr 18, 385-411.

27. Krawielitzki K, Zebrowska T, Kreienbring F, et al. (1996) Absorption and secretion of exogenous and endogenous $\mathrm{N}$ along the digestive tract and kinetic parameters of protein metabolism in growing pigs. 1. Estimation by digesta exchange between ${ }^{15} \mathrm{~N}$-labelled and unlabelled pigs. J Anim Physiol An N 76, 46-56.

28. Krawielitzki K, Zebrowska T, Schadereit J, et al. (1990) Determining of nitrogen absorption and nitrogen secretion in different sections of the pig's intestine by digesta exchange between ${ }^{15} \mathrm{~N}$ labelled and unlabelled animals. Arch Tierernabr 40, 25-37.

29. Rademacher M, Mosenthin R \& Sauer WC (1995) The use of apparent ileal lysine digestibility in diet formulation for the growing pig. In Proceedings of the 7 th International Symposium on Protein Metabolism and Nutrition, pp. 123-127 [AF Nunes, AV Portugal, JP Costa and JR Ribeiro, editors]. EAAP Publication No. 81.

30. Heger J (2003) Essential to non-essential amino acid ratios. In Amino Acids in Animal Nutrition, pp. 103-124 [JPF D'Mello, editor]. Wallingford, Oxon, UK: CABI.

31. Reeds PJ (2000) Dispensable and indispensable amino acids for humans. J Nutr 130, 1835S-1840S.

32. Torrallardona D, Harris CI \& Fuller MF (2003) Pigs' gastrointestinal microflora provide them with essential amino acids. J Nutr 133, 1127-1131.

33. Torrallardona D, Harris CI \& Fuller MF (2003) Lysine synthesized by the gastrointestinal microflora of pigs is absorbed, mostly in the small intestine. Am J Physiol Endocrinol Metab 284, E1177-E1180.

34. Torrallardona D, Harris CI, Milne E, et al. (1994) The contribution of intestinal microflora to amino acid requirements in pigs. In Proceedings of the 6th International Symposium on Digestive Physiology of Pigs, European Association for Animal Production, pp. 245-248 [WB Souffrant and H Hagemeister, editors]. EAAP Publication No. 80.

35. Tanaka N, Kubo K, Shiraki K, et al. (1980) A pilot-study on protein-metabolism in the Papua-New-Guinea highlanders. J Nutr Sci Vitaminol 26, 247-259.

36. Jackson AA (1995) Salvage of urea-nitrogen and protein requirements. Proc Nutr Soc 54, 535-547.

37. Metges CC, El-Khoury AE, Henneman L, et al. (1999) Availability of intestinal microbial lysine for whole body lysine homeostasis in human subjects. Am J Physiol -Endoc $M$ 277, E597-E607.

38. Metges CC (2000) Contribution of microbial amino acids to amino acid homeostasis of the host. J Nutr 130, 1857S-1864S.

39. Torrallardona D, Harris CI, Coates ME, et al. (1996) Microbial amino acid synthesis and utilization in rats: Incorporation of $\mathrm{N}-15$ from $(\mathrm{NH} 4 \mathrm{Cl})-\mathrm{N}-15$ into lysine in the tissues of germ-free and conventional rats. Br J Nutr 76, 689-700.

40. Stein HH, Fuller MF, Moughan PJ, et al. (2007) Definition of apparent, true, and standardized ileal digestibility of amino acids in pigs. Livest Sci 109, 282-285.

41. Moughan PJ \& Smith WC (1985) Determination and assessment of apparent ileal amino acid digestibility coefficients for the growing pig. New Zeal J Agr Res 28, 365-370.

42. Sauer WC, Just A, Jorgensen HH, et al. (1980) The influence of diet composition on the apparent digestibility of crude protein and amino acids at the terminal ileum and overall in pigs. Acta Agr Scan 30, 449-459.

43. Tanksley TDJ \& Knabe DA (1984) Ileal digestibilities of amino acids in pig feeds and their use in formulating diets. In Recent Advances in Animal Nutrition, pp. 75-94 [W Haresign and DJA Cole, editors]. London, UK: ButterworthHeinemann, Ltd.

44. Low AG, Partridge IG, Keal HD, et al. (1982) A comparison of methods in vitro and in vivo of measuring amino acid digestibility in foodstuffs as predictors of pig growth and carcass composition. Anim Prod 34, 403.

45. Just A, Jorgensen H \& Fernandez JA (1985) Correlation of protein deposited in growing female pigs to ileal and faecal digestible crude protein and amino acids. Livest Prod Sci 12, 145-159.

46. Sauer WC, Stothes SC \& Parker RJ (1977) Apparent and true availabilities of amino acids in wheat and milling byproducts for growing pigs. Can J Anim Sci 5, 775-784.

47. Sauer WC, Kennelly JJ, Aherne FX, et al. (1981) Availabilities of amino acids in corn, wheat and barley for growing pigs. Can J Anim Sci 57, 585-597.

48. Van Weerden EJ, Huisman J, van Leeuwen P, et al. (1985) The sensitivity of the ileal digestibility method as compared to the faecal digestibility method. In Proceedings of the $3 \mathrm{rd}$ International Symposium on Digestive Physiology in Pigs, pp. 392-395 [A Just, H Jorgensen and JA Fernandez, editors]. Copenhagen, Denmark: National Institute of Animal Science.

49. Dierick NA, Vervaeke IJ, Decuypere JA, et al. (1988) Correlation of ileal and fecal digested protein and organic matter to production performance in growing pigs. Wiss $Z W P U$ Rostock N-Reihe 37, 50-51.

50. Holmes JHG, Bayley HS, Leadbeater PA, et al. (1974) Digestion of protein in small and large intestine of the pig. Br J Nutr 32, 479-489.

51. Austic RE (1983) The availability of amino acids as an attribute of feeds. In Feed Information and Animal Production, pp. 175-189 [GE Robards and RG Packham, editors]. Wallingford, UK: CABI.

52. Fan MZ, Sauer WC, Hardin RT, et al. (1994) Determination of apparent ileal amino acid digestibility in pigs: effect of dietary amino acid level. J Anim Sci 72, 2851-2859.

53. Nyachoti CM, de Lange CFM \& Schulze H (1997) Estimating endogenous amino acid flows at the terminal ileum and true ileal amino acid digestibilities in feedstuffs for growing pigs using the homoarginine method. J Anim Sci 75, 3206-3213.

54. Nyachoti CM, de Lange CFM, McBride BW, et al. (1997) Significance of endogenous gut nitrogen losses in the nutrition of growing pigs: A review. Can J Anim Sci 77, 140-163. 
55. Tamminga S, Schulze H, Van Bruchem J, et al. (1995) The nutritional significance of endogenous N-losses along the gastro-intestinal tract of farm animals. Arch Tierernabr $\mathbf{4 8}$, $9-22$.

56. Eklund M, Mosenthin R, Piepho HP, et al. (2010) Estimates of dietary threshold levels for crude protein and amino acids to obtain plateau values of apparent ileal crude protein and amino acid digestibility in newly weaned pigs. Arch Tierernahr 64, 357-372.

57. Jansman AJM, Smink W, van Leeuwen P, et al. (2002) Evaluation through literature data of the amount and amino acid composition of basal endogenous crude protein at the terminal ileum of pigs. Anim Feed Sci Technol 98, 49-60.

58. Moughan PJ (2003) Simulating the partitioning of dietary amino acids: New directions. J Anim Sci 81, 14 Suppl. 2, E60-E67.

59. NRC (1998) Nutrient Requirements of Swine, 10th ed. National Academy Press: NW, Washington, D.C.

60. CVB (Centraal Veevoederbureau) (2003) Veevoedertabel (in Dutch; Nutritional Value of Feed Ingredients). Lelystad, The Netherlands: Centraal Veevoederbureau.

61. Sauvant D, Perez JM \& Tran G (2004) Tables of Composition and Nutritional Value of Feed Materials: Pigs, Poultry, Cattle, Shep, Goats, Rabbits, Horses and Fish. Wageningen, The Netherlands: Wageningen Pers.

62. Furuya S \& Kaji Y (1991) Additivity of apparent and true digestible amino-acid supply in barley, maize, wheat or soybean-meal based diets for growing pigs. Anim Feed Sci Technol 32, 321-331.

63. Seve B, Tran G, Jondreville C, et al. (2000) Measuring ileal basal endogenous losses and digestive utilization of amino acids through ileo-rectal anastomosis in pigs: Ring test between three laboratories. In Proceedings of the 8th International Symposium on Digestive Physiology in Pigs, pp. 195-197 [JE Lindberg and B Ogle, editors]. Oxon, UK: CABI.

64. de Lange CFM, Souffrant WB \& Sauer WC (1990) Real ileal protein and amino acid digestibilities in feedstuffs for growing pigs as determined with the $\mathrm{N}-15$-isotope dilution technique. J Anim Sci 68, 409-418.

65. de Lange CFM, Sauer WC \& Souffrant WB (1989) The effect of protein status of the pig on the recovery and amino acid composition of endogenous protein in digesta collected from the distal ileum. J Anim Sci 67, 755-762.

66. Prawirodigdo S, Batterham ES, Andersen LM, et al. (1997) Nitrogen retention in pigs given diets containing cottonseed meal or soybean meal. Anim Feed Sci Technol 67, 205-211.

67. van Barneveld RJ, Batterham ES \& Norton BW (1994) The effect of heat on amino acids for growing pigs 3. The availability of lysine from heat-treated field peas (Pisum sativum cultivar Dundale) determined using the slope-ratio assay. Br J Nutr 72, 257-275.

68. Rutherfurd SM \& Moughan PJ (1997) Application of a new method for determining digestible reactive lysine to variably heated protein sources. J Agric Food Chem 45, 1582-1586.

69. Rutherfurd SM, Moughan PJ \& Morel PCH (1997) Assessment of the true ileal digestibility of reactive lysine as a predictor of lysine uptake from the small intestine of the growing pig. J Agric Food Chem 45, 4378-4383.

70. Moughan PJ \& Rutherfurd SM (2008) Available lysine in foods: A brief historical overview. J AOAC Int 91, 901-906.

71. Rutherfurd SM \& Moughan PJ (2011) Available versus digestible amino acids. Br J Nutr 108, S298-S305.

72. Dierick NA, Vervaeke IJ, Decuypere JA, et al. (1986) Influence of the gut flora and of some growth-promoting feed additives on nitrogen-metabolism in pigs. 1. Studies in vitro. Livest Prod Sci 14, 161-176.
73. Souffrant WB (2001) Effect of dietary fibre on ileal digestibility and endogenous nitrogen losses in the pig. Anim Feed Sci Technol 90, 93-102.

74. Morel PCH, Padilla RM \& Ravindran G (2003) Effect of nonstarch polysaccharides on mucin secretion and endogenous amino acid losses in pigs. Asian-Aust J Anim Sci 16, $1332-1338$.

75. Mosenthin R, Sauer WC \& Ahrens F (1994) Dietary pectin's effect on ileal and fecal amino acid digestibility and exocrine pancreatic secretions in growing pigs. J Nutr 124, 1222-1229.

76. Libao-Mercado AJ, Leeson S, Langer S, et al. (2006) Efficiency of utilizing ileal digestible lysine and threonine for whole body protein deposition in growing pigs is reduced when dietary casein is replaced by wheat shorts. J Anim Sci $\mathbf{8 4}$, $1362-1374$.

77. Zhu CL, Rademacher M \& de Lange CFM (2005) Increasing dietary pectin level reduces utilization of digestible threonine intake, but not lysine intake, for body protein deposition in growing pigs. J Anim Sci 83, 1044-1053.

78. Libao-Mercado AJ, Zhu CL, Fuller MF, et al. (2007) Effect of feeding fermentable fiber on synthesis of total and mucosal protein in the intestine of the growing pig. Livest Sci 109, $125-128$.

79. Hedemann MS, Theil PK \& Bach Knudsen KE (2009) The thickness of the intestinal mucous layer in the colon of rats fed various sources of non-digestible carbohydrates is positively correlated with the pool of SCFA but negatively correlated with the proportion of butyric acid in digesta. Br J Nutr 102, 117-125.

80. Lien KA, Sauer WC \& He HE (2001) Dietary influences on the secretion into and degradation of mucin in the digestive tract of monogastric animals and humans. J Anim Feed Sci 10, $223-245$.

81. Zhu CL, Lapierre H, Rademacher M, et al. (2003) Pectin infusion into the caecum reduces the utilization of threonine intake for body protein deposition and urea flux in growing pigs. In 9th International Symposium on Digestive Physiology in Pigs, pp. 346-348 [RO Ball, editor]. Alberta, Canada: University of Alberta.

82. Zhu CL, Rademacher M \& de Lange CFM (2007) Intake of fermentable fibre and body protein deposition in pigs fed methionine or tryptophan limiting diets. In 2nd International Symposium on Energy and Protein Metabolism and Nutrition, pp. 553-554 [I Ortigues-Marty, N Miraux and W Brand-Williams, editors]. EAAP Publication No. 124.

83. Oba M \& Allen MS (2003) Effects of diet fermentability on efficiency of microbial nitrogen production in lactating dairy cows. J Dairy Sci 86, 195-207.

84. Wenk C (2001) The role of dietary fibre in the digestive physiology of the pig. Anim Feed Sci Technol 90, 21-33.

85. Libao-Mercado AJ (2007) Enteric Fermentation and Intestinal Nitrogen Metabolism in the Growing Pig, $\mathrm{PhD}$ ed. Ontario, Canada: University of Guelph.

86. Wu G (2009) Amino acids: metabolism, functions, and nutrition. Amino Acids 37, 1-17.

87. Smith EA \& Macfarlane GT (1997) Dissimilatory amino acid metabolism in human colonic bacteria. Anaerobe 3, 327-337.

88. Hess V \& Seve B (2000) Consequences of ileal endogenous losses on body protein retention and feedstuff evaluation. In Proceedings of the 8th International Symposium on Digestive Physiology in Pigs, pp. 133-135 [JE Lindberg and B Ogle, editors]. Oxon, UK: CABI.

89. Lahaye L, Ganier P, Thibault JN, et al. (2004) Technological processes of feed manufacturing affect protein endogenous losses and amino acid availability for body protein deposition in pigs. Anim Feed Sci Technol 113, 141-156. 